\title{
Maternal obesity as a risk factor for early childhood type 1 diabetes: a nationwide, prospective, population-based case-control study
}

\author{
Nina Lindell ${ }^{1,2}$ • Annelie Carlsson ${ }^{3}$ • Ann Josefsson ${ }^{1,2}$ • Ulf Samuelsson ${ }^{2,4}$
}

Received: 10 August 2017 / Accepted: 25 September 2017 /Published online: 2 November 2017

(C) The Author(s) 2017. This article is an open access publication

\begin{abstract}
Aims/hypothesis Genetic and environmental factors are believed to cause type 1 diabetes. The aim of this study was to investigate the influence of maternal BMI and gestational weight gain on the subsequent risk of childhood type 1 diabetes.

Methods Children in the Swedish National Quality Register for Diabetes in Children were matched with control children from the Swedish Medical Birth Register. Children were included whose mothers had data available on BMI in early pregnancy and gestational weight gain, giving a total of 16,179 individuals: 3231 children with type 1 diabetes and 12,948 control children.

Results Mothers of children with type 1 diabetes were more likely to be obese $(9 \%[n=292 / 3231]$ vs $7.7 \%[n=991 /$ $12,948] ; p=0.02)$ and/or have diabetes themselves $(2.8 \%$ $[n=90 / 3231]$ vs $0.8 \%[n=108 / 12,948] ; p<0.001)$ compared with mothers of control children. Gestational weight gain did not differ significantly between the two groups of mothers. In mothers without diabetes, maternal obesity was a significant risk factor for type 1 diabetes in the offspring $(p=0.04)$. A child had an increased risk of developing type 1 diabetes if the mother had been obese in early pregnancy (crude OR 1.20;
\end{abstract}

Nina Lindell

nina.lindell@liu.se

1 Department of Obstetrics and Gynaecology, Linköping University, S-581 85 Linköping, Sweden

2 Department of Clinical and Experimental Medicine, Linköping University, Linköping, Sweden

3 Department of Clinical Sciences, Lund University, Skåne University Hospital, Lund, Sweden

4 Division of Paediatrics, Linköping University, Linköping, Sweden
95\% CI 1.05, 1.38; adjusted OR 1.18; 95\% CI 1.02, 1.36). Among children with type 1 diabetes $(n=3231)$ there was a difference $(p<0.001)$ in age at onset in relation to the mother's BMI. Among children in the oldest age group (1519 years), there were more mothers who had been underweight during pregnancy, while in the youngest age group ( $0-4$ years) the pattern was reversed.

Conclusions/interpretation Maternal obesity, in the absence of maternal diabetes, is a risk factor for type 1 diabetes in the offspring, and influences the age of onset of type 1 diabetes. This emphasises the importance of a normal maternal BMI to potentially decrease the incidence of type 1 diabetes.

Keywords Age at onset · BMI - Gestational weight gain . Obesity $\cdot$ Pregnancy $\cdot$ Type 1 diabetes

$\begin{array}{ll}\text { Abbreviations } & \\ \text { IOM } & \text { Institute of Medicine } \\ \text { MBR } & \text { Swedish Medical Birth Register } \\ \text { SALAR } & \text { Association of Local Authorities and } \\ & \begin{array}{l}\text { Regions } \\ \text { SWEDIABKIDS }\end{array} \\ \begin{array}{l}\text { Swedish National Quality Register for } \\ \text { Diabetes in Children }\end{array}\end{array}$

\section{Introduction}

Type 1 diabetes is one of the most common chronic diseases in children and young adults, and the incidence has increased worldwide in recent decades [1, 2]. Since the 1980s, the increase has been around 3\% annually and the disease currently affects about 500,000 children worldwide [3]. Second to Finland, Sweden has the highest incidence of type 1 diabetes in the world [2]. About $2 \%$ of children with diabetes in 
Sweden are diagnosed with type 2 diabetes [4]. The aetiology of type 1 diabetes is multifactorial, and both genetic and environmental factors are thought to contribute [5]. The period in which the rapid increase has occurred is too short to be explained by genetic shifts, and is therefore believed to be influenced by environmental factors [6].

In parallel with the increased incidence of type 1 diabetes, a significant increase in obesity in the general population has been observed worldwide. In the USA almost $35 \%$ of women aged 20-39 are obese [7] and 48\% of US women start their pregnancy being overweight [8]. In Sweden the number of pregnant obese women has doubled since the 1990s; in $2013,25 \%$ of women were overweight and $13 \%$ were obese in early pregnancy [9]. Some studies have shown a relationship between high maternal pre-gestational BMI and high gestational weight gain and subsequent risk of insulin resistance, obesity and type 2 diabetes in the offspring [10-12]. Only a few studies, however, have looked at maternal BMI and/or gestational weight gain and subsequent risk of type 1 diabetes in the offspring, and such studies have produced conflicting results [5, 13-18].

The aim of this study was to further investigate the possible effect of maternal BMI and gestational weight gain on the subsequent risk of childhood type 1 diabetes in the offspring, using data from the Swedish National Quality Register for Diabetes in Children (SWEDIABKIDS) and the Swedish Medical Birth Register (MBR).

\section{Methods}

SWEDIABKIDS is a national quality register (https:// swediabkids.ndr.nu/) [19] that includes approximately $99 \%$ of children and adolescents with diabetes in Sweden. It was introduced stepwise and randomly in Sweden during 20002007, and since 2007 all outpatient attendance, in all 42 paediatric clinics, has been entered in the register. The diabetes teams include all individuals from the time of diagnosis, and the data are thereafter prospectively reported. This means that if a diabetes team began reporting to the registry in 2005, all their patients below 18 years of age were included, not only those newly diagnosed. The data from the time of diabetes onset including every patient visit are then prospectively followed. According to the Swedish guidelines, children with diabetes visit the diabetes centre at least four times a year. In Sweden, paediatric clinics treat all children and adolescents aged $0-18$ years with diabetes from defined geographic areas. On 31 December 2016, the register included data from 391,164 outpatient visits, in total 19,121 patients (data from U. Samuelsson, one of the keepers of the registry). SWEDIABKIDS is financially supported by the Association of Local Authorities and Regions (SALAR), which represents the governmental, professional and employer-related interests of Sweden's municipalities, county councils and regions (http://english.skl.se). In Sweden, all newly diagnosed children and adolescents with type 1 diabetes and their parents are informed and give oral consent before being registered in SWEDIABKIDS. They can choose not to participate.

The MBR contains information on more than $98 \%$ of all births in Sweden since 1973 [20]. The register is based on the medical charts from antenatal, obstetric and neonatal care. In Sweden it is mandatory for all pregnant women to be registered in the MBR. The woman's personal identification number was used to collect information about her weight and height in early pregnancy, her weight at delivery, parity, gestational week at childbirth and smoking habits. In addition, information about maternal diabetes corresponding to the diagnostic code $\mathrm{O} 24$ in ICD-10 (www.who.int/classifications/icd/en) was collected. In 1997, the MBR started to report the different types of diabetes, i.e. O24.0 pre-existing type 1 diabetes, O24.1 pre-existing type 2 diabetes and $\mathrm{O} 24.4$ gestational diabetes. Before that the diagnosis of diabetes was not further specified.

Study population The study population comprised children and adolescents in SWEDIABKIDS, aged 0-19 years (only one individual in the register was aged 19 years) and diagnosed with type 1 diabetes between January 2000 and October $2012(n=9376)$. The diagnosis and classification of diabetes are initially based on clinical symptoms and signs, and from 2005 were strengthened by information on diabetes-related autoantibodies, HLA types, C-peptide and, in some cases, screening for MODY genetics [21]. Since the clinical diagnosis is rarely changed due to the additional information, we conclude that the diagnoses before 2005 are adequate. All children with diabetes were matched with four control children from the MBR with the same year and day of birth, same sex, and born in the same region of Sweden. In this study we included the children for whom data on their mother's BMI in early pregnancy and gestational weight gain were available. In total, there were 16,179 individuals: 3231 children with type 1 diabetes and 12,948 control children. The children were born between 1982 and 2011; the majority were born between 1990 and 2011 (93.2\%). Boys comprised 55.5\%, girls 44.5\%. In MBR there is missing data for 416 women (2.6\%) on smoking during pregnancy.

The study was approved by the regional ethics review board in Linköping (Dnr 2011/381-31), prior to any data collection.

Statistic analyses Women were categorised into four BMI groups: underweight (BMI $<18.5 \mathrm{~kg} / \mathrm{m}^{2}$ ), normal weight (BMI 18.5-24.9 kg/m²), overweight (BMI $25.0-29.9 \mathrm{~kg} / \mathrm{m}^{2}$ ) and obese (BMI $\geq 30.0 \mathrm{~kg} / \mathrm{m}^{2}$ ), according to the WHO classification of BMI cut-off values [22]. Each BMI class has a recommended gestational weight gain according to the 2009 
guidelines of the US Institute of Medicine (IOM) and the US National Research Council [23]. For underweight women it is $12.5-18.0 \mathrm{~kg}$, for normal weight women it is $11.5-16.0 \mathrm{~kg}$, for overweight women it is $7.0-11.5 \mathrm{~kg}$ and for obese women it is $5.0-9.0 \mathrm{~kg}$. Weight gain within these recommendations is categorised as adequate, weight gain below is categorised as inadequate, and weight gain above is categorised as excessive.

The $\chi^{2}$ test was used to analyse the univariate relationship between maternal characteristics, such as BMI, weight gain and age, and the proportion of children who developed type 1 diabetes. The $\chi^{2}$ test was also used to assess the association between type 1 diabetes in different age groups in relation to maternal BMI. Multivariate analysis included multiple logistic regression in which the dependent variable was type 1 diabetes in the child, and independent variables were BMI in early pregnancy, maternal age at delivery, maternal diabetes, parity, smoking during pregnancy, gestational weight gain and pregnancy length (Table 3). All statistical analyses were performed using IBM SPSS, version 23 (IBM, Armonk, NY, USA). A $p$ value of $<0.05$ (two-sided) was considered statistically significant.

\section{Results}

Mothers of index children were more likely to be obese $(p=0.02)$, older $(p=0.02)$ and/or have diabetes themselves $(p<0.001)$, but were less likely to be smokers $(p=0.04)$, compared with mothers of control children. The pregnancy length and parity of the mothers did not significantly differ between the groups, nor did gestational weight gain (Table 1). This finding remained when only mothers who delivered at term were included in the analysis (data not shown). However, further analysis showed that underweight mothers with an inadequate gestational weight gain were less likely to have a child who developed type 1 diabetes compared with underweight mothers with adequate $(p=0.04)$ or excessive $(p=0.04)$ gestational weight gain. Only one underweight mother with an inadequate weight gain had diabetes.

There was a significant difference $(p<0.001)$ in the distribution of BMI between women with gestational diabetes mellitus and type 1 diabetes and women without diabetes. None of the mothers in the study were diagnosed with type 2 diabetes. Almost $30 \%(27.1 \%)$ of women with gestational diabetes mellitus were obese, whereas only $14.9 \%$ of women with type 1 diabetes and $11.2 \%$ of women without diabetes were obese (data not shown).

A subgroup analysis comparing offspring of non-diabetic mothers revealed that children who developed type 1 diabetes more often had obese mothers compared with control children $(8.8 \%$ vs $7.6 \% ; p=0.04)$. However, this increased risk was not seen in the offspring of diabetic mothers (Table 2), regardless of whether the mother had type 1 diabetes or gestational diabetes (data not shown).

In the multivariate analysis (Table 3 ) a child whose mother had been obese in early pregnancy had an increased risk of developing type 1 diabetes (crude OR 1.20; 95\% CI 1.05, 1.38; adjusted OR 1.18; 95\% CI 1.02, 1.36). An inadequate gestational weight gain seemed to be a protective factor (crude OR $0.9 ; 95 \%$ CI $0.81,0.99$ ); however, the significance disappeared in the adjusted model, as did the increased risk seen with higher maternal age as well as the seemingly decreased risk seen with maternal smoking during pregnancy.

Maternal diabetes was the strongest risk factor (crude OR $3.41 ; 95 \%$ CI 2.57, 4.52; adjusted OR 3.31; 95\% CI 2.49, 4.40) for the offspring to develop type 1 diabetes (Table 3). A subgroup analysis of women pregnant in 1997 and thereafter, with type 1 diabetes $(n=67)$ or gestational diabetes $(n=70)$, revealed that maternal type 1 diabetes contributed the highest risk of the child developing type 1 diabetes (crude OR 5.13; 95\% CI 3.16, 8.33; adjusted OR 4.75; 95\% CI 2.19, 7.75). Gestational diabetes also increased the risk (crude OR 1.78; 95\% CI 1.07, 2.98; adjusted OR 1.81; 95\% CI 1.08, 3.04). There were no significant interactions between BMI, parity, maternal age, maternal diabetes and pregnancy length.

Among children with type 1 diabetes $(n=3231)$ there was a difference $(p<0.001)$ in age at onset of type 1 diabetes with regard to the mother's BMI. As seen in Fig. 1, maternal BMI had no obvious impact on the incidence of children diagnosed with type 1 diabetes between 10 and 14 years of age. On the other hand, in children diagnosed below this age there was a clear tendency of increasing incidence of type 1 diabetes with higher maternal BMI. For the oldest age group the pattern was reversed. These findings were the same for both boys and girls. However, further analysis showed that the observed differences were only seen for non-diabetic mothers, whereas there was no significant difference if the mothers had diabetes (data not shown).

\section{Discussion}

In this nationwide, prospective, population-based case-control study we found that maternal obesity in early pregnancy significantly increased the risk of type 1 diabetes in the offspring of mothers without diabetes. Gestational weight gain did not seem to influence the risk. Maternal obesity also correlated with early onset ( $0-4$ years) of type 1 diabetes in the offspring. The strongest risk factor for type 1 diabetes was, however, maternal diabetes, especially type 1 diabetes, but gestational diabetes also increased the risk.

Our results strengthen the findings of a recent cohort study from Sweden which showed that high first trimester maternal BMI in women without diabetes was associated with an increased risk of type 1 diabetes in their offspring [18]. As also 
Table 1 Maternal characteristics of children with and without type 1 diabetes

\begin{tabular}{|c|c|c|c|}
\hline Maternal characteristic & $\begin{array}{l}\text { Control children } \\
(n=12,948)\end{array}$ & $\begin{array}{l}\text { Index children } \\
(n=3231)\end{array}$ & $p$ value $^{\mathrm{a}}$ \\
\hline \multicolumn{4}{|l|}{ BMI } \\
\hline Underweight $\left(<18.5 \mathrm{~kg} / \mathrm{m}^{2}\right)$ & $530(4.1)$ & $110(3.4)$ & \multirow[t]{4}{*}{0.02} \\
\hline Normal weight (18.5-24.9 kg/m²) & $8769(67.7)$ & $2149(66.5)$ & \\
\hline Overweight $\left(25.0-29.9 \mathrm{~kg} / \mathrm{m}^{2}\right)$ & $2658(20.5)$ & $680(21.1)$ & \\
\hline Obese $\left(\geq 30.0 \mathrm{~kg} / \mathrm{m}^{2}\right)$ & $991(7.7)$ & $292(9.0)$ & \\
\hline \multicolumn{4}{|l|}{ Weight gain according to IOM } \\
\hline Inadequate & $3127(24.2)$ & $717(22.2)$ & \multirow[t]{3}{*}{0.06} \\
\hline Adequate & $5091(39.3)$ & $1301(40.3)$ & \\
\hline Excessive & $4730(36.5)$ & $1213(37.5)$ & \\
\hline \multicolumn{4}{|l|}{ Maternal age } \\
\hline $13-29$ years & $7492(57.9)$ & $1794(55.5)$ & \multirow[t]{2}{*}{0.02} \\
\hline$\geq 30$ years & $5456(42.1)$ & $1437(44.5)$ & \\
\hline \multicolumn{4}{|l|}{ Pregnancy length } \\
\hline Very preterm (<32 weeks) & $53(0.4)$ & $10(0.3)$ & \multirow[t]{4}{*}{0.24} \\
\hline Moderately preterm (32-36 weeks) & $561(4.3)$ & $164(5.1)$ & \\
\hline Term (37-42 weeks) & $12,262(94.7)$ & $3037(94.0)$ & \\
\hline Post-term (>42 weeks) & $72(0.6)$ & $20(0.6)$ & \\
\hline \multicolumn{4}{|l|}{ Parity } \\
\hline Primipara & $5681(43.9)$ & $1389(43.0)$ & \multirow[t]{2}{*}{0.36} \\
\hline Multipara & $7267(56.1)$ & $1842(57.0)$ & \\
\hline \multicolumn{4}{|l|}{ Smoking during pregnancy } \\
\hline No & $9971(79.1)$ & $2551(80.8)$ & \multirow[t]{2}{*}{0.04} \\
\hline Yes, at any time during pregnancy & $2634(20.9)$ & $607(19.2)$ & \\
\hline \multicolumn{4}{|l|}{ Maternal diabetes } \\
\hline No & $12,840(99.2)$ & $3141(97.2)$ & \multirow[t]{2}{*}{$<0.001$} \\
\hline Yes, any form of diabetes & $108(0.8)$ & $90(2.8)$ & \\
\hline
\end{tabular}

Data are given as $n(\%)$. In MBR there is missing data for 416 women (2.6\%) on smoking during pregnancy ${ }^{\mathrm{a}} \chi^{2}$ test: control children vs index children shown in our case-control study, maternal type 1 diabetes and gestational diabetes were risk factors for type 1 diabetes in the offspring [18]. In addition, our study investigated whether age at diabetes onset had any correlation with maternal obesity. In
2009 , Rasmussen et al showed that maternal obesity and gestational weight gain $\geq 15 \mathrm{~kg}$ increased the risk of islet autoimmunity two- to threefold in offspring with a high genetic susceptibility for type 1 diabetes [5]. Furthermore, a recent study
Table 2 Risk of type 1 diabetes in offspring in relation to maternal diabetes and BMI class

\begin{tabular}{lllllc}
\hline $\begin{array}{l}\text { Maternal BMI class in early } \\
\text { pregnancy }\end{array}$ & \multicolumn{2}{l}{$\begin{array}{l}\text { No maternal diabetes } \\
(n=15,981)^{\dagger}\end{array}$} & & \multicolumn{2}{l}{ Maternal diabetes $(n=198)^{\ddagger}$} \\
\cline { 2 - 3 } \cline { 5 - 6 } & $\begin{array}{l}\text { Control } \\
\text { children }\end{array}$ & $\begin{array}{l}\text { Index } \\
\text { children }\end{array}$ & & $\begin{array}{l}\text { Control } \\
\text { children }\end{array}$ & $\begin{array}{l}\text { Index } \\
\text { children }\end{array}$ \\
\hline Underweight $\left(<18.5 \mathrm{~kg} / \mathrm{m}^{2}\right)$ & $529(4.1)$ & $110(3.5)$ & & $1(0.9)$ & $0(0.0)$ \\
Normal weight $\left(18.5-24.9 \mathrm{~kg} / \mathrm{m}^{2}\right)$ & $8711(67.8)$ & $2100(66.9)$ & & $58(53.7)$ & $49(54.4)$ \\
Overweight $\left(25.0-29.9 \mathrm{~kg} / \mathrm{m}^{2}\right)$ & $2628(20.5)$ & $654(20.8)$ & $30(27.8)$ & $26(28.9)$ \\
Obese $\left(\geq 30.0 \mathrm{~kg} / \mathrm{m}^{2}\right)$ & $972(7.6)$ & $277(8.8)$ & $19(17.6)$ & $15(16.7)$ \\
\hline
\end{tabular}

Data are given as $n(\%)$

${ }^{\dagger} p=0.04$

${ }^{\ddagger} p=0.83$ 
Table 3 Logistic regression model with ORs for developing type 1 diabetes

\begin{tabular}{|c|c|c|}
\hline Maternal characteristic & Crude OR $(95 \% \mathrm{CI})$ & Adjusted OR (95\% CI) \\
\hline \multicolumn{3}{|l|}{ BMI } \\
\hline Underweight $\left(<18.5 \mathrm{~kg} / \mathrm{m}^{2}\right)$ & $0.85(0.69,1.05)$ & $0.89(0.71,1.10)$ \\
\hline Normal weight $\left(18.5-24.9 \mathrm{~kg} / \mathrm{m}^{2}\right)$ & 1.00 & \\
\hline Overweight (25.0-29.9) & $1.04(0.95,1.15)$ & $1.01(0.91,1.12)$ \\
\hline Obese $\left(\geq 30.0 \mathrm{~kg} / \mathrm{m}^{2}\right)$ & $1.20(1.05,1.38)$ & $1.18(1.02,1.36)$ \\
\hline \multicolumn{3}{|l|}{ Weight gain according to IOM } \\
\hline Inadequate & $0.90(0.81,0.99)$ & $0.90(0.81,1.00)$ \\
\hline Adequate & 1.00 & \\
\hline Excessive & $1.00(0.92,1.10)$ & $0.99(0.90,1.09)$ \\
\hline \multicolumn{3}{|l|}{ Maternal age } \\
\hline $13-29$ years & 1.00 & \\
\hline$\geq 30$ years & $1.10(1.02,1.19)$ & $1.08(0.99,1.17)$ \\
\hline \multicolumn{3}{|l|}{ Pregnancy length } \\
\hline Very preterm (<32 weeks) & $0.76(0.39,1.50)$ & $0.65(0.33,1.38)$ \\
\hline Moderately preterm (32-36 weeks) & $1.18(0.99,1.41)$ & $1.15(0.96,1.38)$ \\
\hline Term $(37-42)$ & 1.00 & \\
\hline Post-term (>42 weeks) & $1.12(0.68,1.84)$ & $1.07(0.63,1.80)$ \\
\hline \multicolumn{3}{|l|}{ Parity } \\
\hline Primipara & 1.00 & \\
\hline Multipara & $1.04(0.96,1.12)$ & $1.01(0.93,1.10)$ \\
\hline \multicolumn{3}{|l|}{ Smoking during pregnancy } \\
\hline No & 1.00 & \\
\hline Yes, at any time during pregnancy & $0.90(0.82,0.99)$ & $0.91(0.82,1.00)$ \\
\hline \multicolumn{3}{|l|}{ Maternal diabetes } \\
\hline No & 1.00 & \\
\hline Yes, any form of diabetes & $3.41(2.57,4.52)$ & $3.31(2.49,4.40)$ \\
\hline
\end{tabular}

Adjusted OR includes maternal BMI, gestational weight gain, maternal age, pregnancy length, maternal parity, maternal smoking habits and maternal diabetes of a non-obese diabetic mouse model showed that the offspring of obese mice, compared with those of non-obese mice,

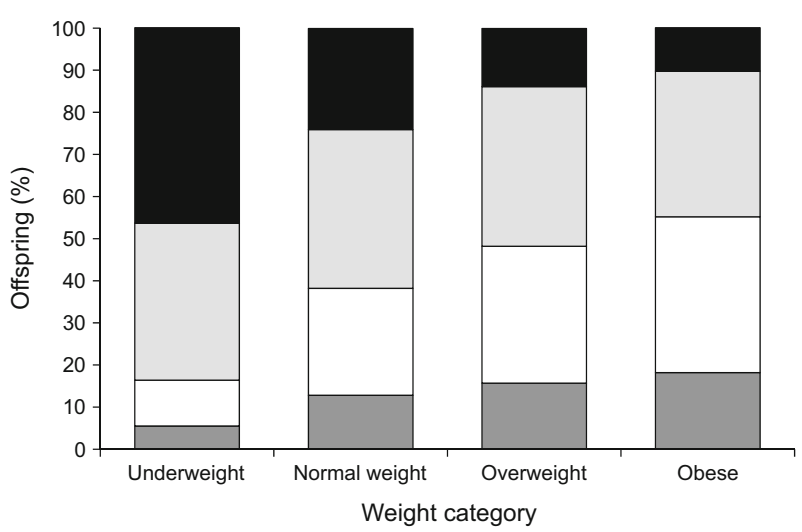

Fig. 1 Maternal BMI in early pregnancy in relation to child's age at onset of type 1 diabetes $(n=3231)$. Weight categories: underweight (BMI $<18.5 \mathrm{~kg} / \mathrm{m}^{2}$ ), normal weight (BMI $18.5-24.9 \mathrm{~kg} / \mathrm{m}^{2}$ ), overweight (BMI $25.0-29.9 \mathrm{~kg} / \mathrm{m}^{2}$ ) and obese (BMI $\geq 30.0 \mathrm{~kg} / \mathrm{m}^{2}$ ). Age of child: dark grey bars, $0-4$ years; white bars, 5-9 years; light grey bars, 10-14 years; black bars, $15-19$ years $(p<0.001$; in underweight vs obese mothers the significance level increases further) had a significantly increased risk of insulitis and inflammation in the pancreas, impaired glucose tolerance and lower serum insulin [24]. The fact that several other studies [14-16] have failed to show a correlation between obesity and type 1 diabetes in the offspring might be due to their small size.

Consistent with previous studies [18, 19], our results showed that maternal type 1 diabetes was a strong risk factor for type 1 diabetes in the offspring. We also found that gestational diabetes increased the risk of type 1 diabetes in the offspring, a result which is in line with some studies [18], but which was somewhat less anticipated. The increased risk with gestational diabetes mellitus could be explained by many different factors. The risk of gestational diabetes mellitus increases with higher maternal BMI. A meta-analysis of 20 studies showed that the increased risks (OR) of developing gestational diabetes mellitus were 2.14 (95\% CI 1.82, 2.53) among overweight, 3.56 (95\% CI 3.05, 4.21) among obese and 8.56 (95\% CI 5.07, 16.04) among severely obese women compared with normal weight pregnant women [25]. The increased risk of type 1 diabetes in the offspring could therefore be attributed to elevated glucose levels or epigenetic effects, as 
described below. Women with gestational diabetes mellitus are at high risk of developing type 2 diabetes and this genetic trait may also be a risk factor for type 1 diabetes in the offspring [26]. The increased risk could also be related to the subset of gestational diabetes that is thought to be autoimmune [27].

Type 1 diabetes has a strong genetic component and studies have revealed a 40-50\% risk for monozygotic twins [28]. About $60 \%$ of the genetic susceptibility is explained by HLA [29]. Our results indicate that the genetic susceptibility for type 1 diabetes, in this case maternal diabetes, is superior to the risk increase conveyed by maternal obesity. However, in the absence of genetic risk, maternal obesity presents as a tangible risk factor which also seems to influence the onset of the disease.

Both diabetes and obesity correlate with higher blood glucose levels. Maternal glucose freely crosses the placenta, but insulin does not. Fetuses of mothers who are either diabetic or obese are therefore subjected to higher circulating glucose levels, prompting increased fetal insulin secretion [11]. Studies have shown that active pancreatic beta cells are more susceptible to destruction $[17,30]$, indicating that the overstimulated fetal beta cells are more prone to processes causing type 1 diabetes, and this might also influence when the child develops the disease. Animal studies have also shown that the metabolic imprinting caused by the obese and diabetic intrauterine environment can be transmitted across generations. The epigenome is especially vulnerable to alterations during gestation because the DNA methylation patterning required for normal tissue development is established and the DNA synthesis rate is high [12].

To our knowledge this is the first study that has investigated the correlation between maternal BMI and age at onset of type 1 diabetes in the offspring. Studies have shown that the largest increase in type 1 diabetes is in the youngest age group (04 years) [31]. One explanation for this could be the influence of maternal obesity. It is known that the pace of disease progress, from trigger to clinical disease, can vary [32]. It could be that children of obese mothers progress faster or that children of underweight women are not exposed to a necessary trigger or accelerant. In view of the growing obesity epidemic, these results highlight the importance of preventive work to reduce overweight and obesity in reproductive age women as a means to decrease the incidence of type 1 diabetes.

Our study failed to confirm an association between gestational weight gain and type 1 diabetes in the offspring. This is in accordance with most studies [13] but not with that of Rasmussen et al [5]. The latter, however, investigated children with high susceptibility for type 1 diabetes, which might be a reason for the diverging results. Also, in this study we were only able to look at the total gestational weight gain, not the rate of gestational weight gain or whether a high weight gain early or late in pregnancy could be a risk factor for type 1 diabetes in the offspring.
In the univariate and unadjusted multivariate analyses, maternal age 30 years and above seemed to be a risk factor for childhood type 1 diabetes, just as some previous studies have shown [33]. However, this correlation disappeared in the adjusted model, in accordance with findings in other studies [14, 16]. Our finding that smoking may protect against type 1 diabetes is not a novel association. Several studies have reported this before, and it is possible that maternal smoking could somehow influence the immune system or DNA methylation in the offspring [13, 16, 33]. However, maternal smoking may also just be another confounding factor and our result should be interpreted with caution. The fact that certain risk factors seem to influence each other might help to explain the conflicting evidence from previous studies.

The major strengths of using data from national registries are the large quantity of prospectively collected data and the fact that population-based information is free from recall bias. It is also possible to investigate confounding factors and adjust the analysis. However, there may of course be other potential confounders, such as paternal diabetes, but unfortunately we do not have access to this information. Register data can involve misclassification problems caused by incorrect registration of diagnostic codes, and this might have affected the validity of the data used in our study. If so, the incorrect registration is random and not systematic. BMI was calculated from self-reported height, whereas weight was sometimes measured and sometimes self-reported. Self-reported data can bias the results, but as individuals tend to over-report their height and under-report their weight any potential bias would probably underestimate the risks associated with maternal obesity.

In conclusion, maternal obesity, in the absence of maternal diabetes, is a risk factor for the development of type 1 diabetes in the offspring and it also influences the age of diabetes onset in the affected child. As mentioned above, this emphasises the importance of preventive work to maintain normal weight among women of reproductive age as a means to potentially decrease the incidence of type 1 diabetes.

Acknowledgements We thank M. Bladh (Linköping University, Linköping, Sweden) for help with the statistical analyses. We also thank all the Swedish paediatric diabetes teams that every year report data to SWEDIABKIDS, and the staff at the maternity wards who report data to the MBR. Without these data this study would not have been possible.

Data availability Data are available from the corresponding author on request.

Funding SWEDIABKIDS is financially supported by SALAR. This study was also supported by ALF Grants, Region Östergötland. The study sponsors were not involved in the design of the study; the collection, analysis and interpretation of data; writing the report; or the decision to submit the report for publication. 
Duality of interest The authors declare that there are no conflicts of interest associated with this manuscript.

Contribution statement US, AJ and AC were responsible for the study concept and acquisition of data. NL and US designed and performed the statistical analyses. NL and US wrote the first draft of the manuscript. All authors edited and reviewed the manuscript and approved the final version. US is the guarantor of this manuscript.

Open Access This article is distributed under the terms of the Creative Commons Attribution 4.0 International License (http:// creativecommons.org/licenses/by/4.0/), which permits unrestricted use, distribution, and reproduction in any medium, provided you give appropriate credit to the original author(s) and the source, provide a link to the Creative Commons license, and indicate if changes were made.

\section{References}

1. Patterson CC, Dahlquist GG, Gyurus E, Green A, Soltesz G, Group ES (2009) Incidence trends for childhood type 1 diabetes in Europe during 1989-2003 and predicted new cases 2005-20: a multicentre prospective registration study. Lancet 373:2027-2033

2. Berhan Y, Waernbaum I, Lind T, Mollsten A, Dahlquist G, Swedish Childhood Diabetes Study Group (2011) Thirty years of prospective nationwide incidence of childhood type 1 diabetes: the accelerating increase by time tends to level off in Sweden. Diabetes 60: 577-581

3. Patterson C, Guariguata L, Dahlquist G, Soltesz G, Ogle G, Silink M (2014) Diabetes in the young - a global view and worldwide estimates of numbers of children with type 1 diabetes. Diabetes Res Clin Pract 103:161-175

4. Samuelsson U, Lindblad B, Carlsson A et al (2013) Residual beta cell function at diagnosis of type 1 diabetes in children and adolescents varies with gender and season. Diabetes Metab Res Rev 29: 85-89

5. Rasmussen T, Stene LC, Samuelsen SO et al (2009) Maternal BMI before pregnancy, maternal weight gain during pregnancy, and risk of persistent positivity for multiple diabetes-associated autoantibodies in children with the high-risk HLA genotype: the MIDIA study. Diabetes Care 32:1904-1906

6. Hasham A, Tomer Y (2011) The recent rise in the frequency of type 1 diabetes: who pulled the trigger? J Autoimmun 37:1-2

7. Ogden CL, Carroll MD, Kit BK, Flegal KM (2014) Prevalence of childhood and adult obesity in the United States, 2011-2012. JAMA 311:806-814

8. Dudenhausen JW, Grunebaum A, Kirschner W (2015) Prepregnancy body weight and gestational weight gain-recommendations and reality in the USA and in Germany. Am J Obstet Gynecol 213:591-592

9. Blomberg $\mathrm{M}$ (2015) Obesity during pregnancy increases the risk for both the woman and child. Skilled care can reduce the increased risk. Lakartidningen 112 [article in Swedish]

10. Maftei O, Whitrow MJ, Davies MJ, Giles LC, Owens JA, Moore VM (2015) Maternal body size prior to pregnancy, gestational diabetes and weight gain: associations with insulin resistance in children at 9-10 years. Diabet Med: J Br Diabet Assoc 32:174-180

11. Lawlor DA (2013) The Society for Social Medicine John Pemberton Lecture 2011. Developmental overnutrition - an old hypothesis with new importance? Int J Epidemiol 42:7-29

12. Dabelea D, Crume T (2011) Maternal environment and the transgenerational cycle of obesity and diabetes. Diabetes 60: $1849-1855$
13. Dahlquist G, Kallen B (1992) Maternal-child blood group incompatibility and other perinatal events increase the risk for early-onset type 1 (insulin-dependent) diabetes mellitus. Diabetologia 35:671675

14. Jones ME, Swerdlow AJ, Gill LE, Goldacre MJ (1998) Pre-natal and early life risk factors for childhood onset diabetes mellitus: a record linkage study. Int J Epidemiol 27:444-449

15. Arkkola T, Kautiainen S, Takkinen HM et al (2011) Relationship of maternal weight status and weight gain rate during pregnancy to the development of advanced beta cell autoimmunity in the offspring: a prospective birth cohort study. Pediatr Diabetes $12: 478-484$

16. Robertson L, Harrild K (2010) Maternal and neonatal risk factors for childhood type 1 diabetes: a matched case-control study. BMC Public Health 10:281

17. Harder T, Roepke K, Diller N, Stechling Y, Dudenhausen JW, Plagemann A (2009) Birth weight, early weight gain, and subsequent risk of type 1 diabetes: systematic review and meta-analysis. Am J Epidemiol 169:1428-1436

18. Hussen HI, Persson M, Moradi T (2015) Maternal overweight and obesity are associated with increased risk of type 1 diabetes in offspring of parents without diabetes regardless of ethnicity. Diabetologia 58:1464-1473

19. Samuelsson U, Lindell N, Bladh M, Akesson K, Carlsson A, Josefsson A (2015) Caesarean section per se does not increase the risk of offspring developing type 1 diabetes: a Swedish populationbased study. Diabetologia 58:2517-2524

20. National Board of Health and Welfare (2002) Report from EpC (Epidemiological centrum) Utvärdering av det svenska medicinska födelseregistret. [Evaluation of the Swedish Medical Birth Register] [article in Swedish] Available from www.socialstyrelsen.se/lists/ artikelkatalog/attachments/10961/2002-112-4_20021124.pdf. Acessed 24 Mar 2016

21. Ludvigsson J, Carlsson A, Forsander G et al (2012) C-peptide in the classification of diabetes in children and adolescents. Pediatr Diabetes 13:45-50

22. James PT, Leach R, Kalamara E, Shayeghi M (2001) The worldwide obesity epidemic. Obes Res 9(Suppl 4):S228-S233

23. Institute of Medicine (US) and National Research Council (US) Committee to Reexamine IOM Pregnancy Guidlines (2009) In: Rasmussen KM, Yaktine AL (eds) Weight gain during pregnancy: reexamining the guidelines. National Academies Press, Washington, DC

24. Wang H, Xue Y, Wang B et al (2014) Maternal obesity exacerbates insulitis and type 1 diabetes in non-obese diabetic mice. Reproduction 148:73-79

25. Chu SY, Callaghan WM, Kim SY et al (2007) Maternal obesity and risk of gestational diabetes mellitus. Diabetes Care 30: 2070-2076

26. Dereke J, Palmqvist S, Nilsson C, Landin-Olsson M, Hillman M (2016) The prevalence and predictive value of the SLC30A8 R325W polymorphism and zinc transporter 8 autoantibodies in the development of GDM and postpartum type 1 diabetes. Endocrine 53:740-746

27. Li Z, Wu TM, Ming WJ, Chen X, Xiao XM (2015) The influence of maternal islet beta-cell autoantibodies in conjunction with gestational hyperglycemia on neonatal outcomes. PLoS One 10: e0120414

28. Cerna M (2008) Genetics of autoimmune diabetes mellitus. Wien Med Wochenschr 158:2-12

29. Larsson HE, Lynch K, Lernmark B et al (2005) Diabetes-associated HLA genotypes affect birthweight in the general population. Diabetologia 48:1484-1491

30. Cardwell CR, Stene LC, Joner G et al (2010) Birthweight and the risk of childhood-onset type 1 diabetes: a meta-analysis of 
observational studies using individual patient data. Diabetologia 53: 641-651

31. Tuomilehto J (2013) The emerging global epidemic of type 1 diabetes. Curr Diab Rep 13:795-804
32. Elding Larsson $\mathrm{H}$ (2016) A Swedish approach to the prevention of type 1 diabetes. Pediatr Diabetes 17(Suppl 22):73-77

33. Stene LC, Gale EA (2013) The prenatal environment and type 1 diabetes. Diabetologia 56:1888-1897 